\title{
Left Fornical Crus Injury and Verbal Memory Impairment in a Patient with Head Trauma
}

\author{
Ji Heon Hong Sung Ho Jang \\ Department of Physical Medicine and Rehabilitation, College of Medicine, Yeungnam University, \\ Daegu, Republic of Korea
}

A 28-year-old man who had suffered a traffic accident underwent conservative management for diffuse axonal injury and intracerebral hemorrhage in the left temporal lobe. Brain MRI (3 months after onset; fig. 1) showed a leukomalactic lesion in the corpus callosum and an old hemorrhage at the left temporal lobe and pons. The Memory Assessment Scale score for verbal memory (86: 18th percentile) was significantly decreased compared with that of visual memory (113: 81th percentile). Diffusion tensor tractography for fornix (fig. 1) showed a disruption of the left fornical crus. The selective verbal memory impairment of this patient seemed to be mainly ascribed to the left fornical crus injury.

\section{Acknowledgement}

This work was supported by the National Research Foundation of Korea Grant funded by the Korean Government (KRF2008-314-E00173).

\section{Suggested Reading}

1 Gaffan EA, Gaffan D, Hodges JR: Amnesia following damage to the left fornix and to other sites: a comparative study. Brain 1991;114:12971313.

2 Jang SH, Kim SH, Kim OL: Fornix injury in a patient with diffuse axonal injury. Arch Neurol 2009;66:1424-1425.

3 Tucker DM, Roeltgen DP, Tully R, Hartmann J, Boxell C: Memory dysfunction following unilateral transection of the fornix: a hippocampal disconnection syndrome. Cortex 1988;24:465-472.

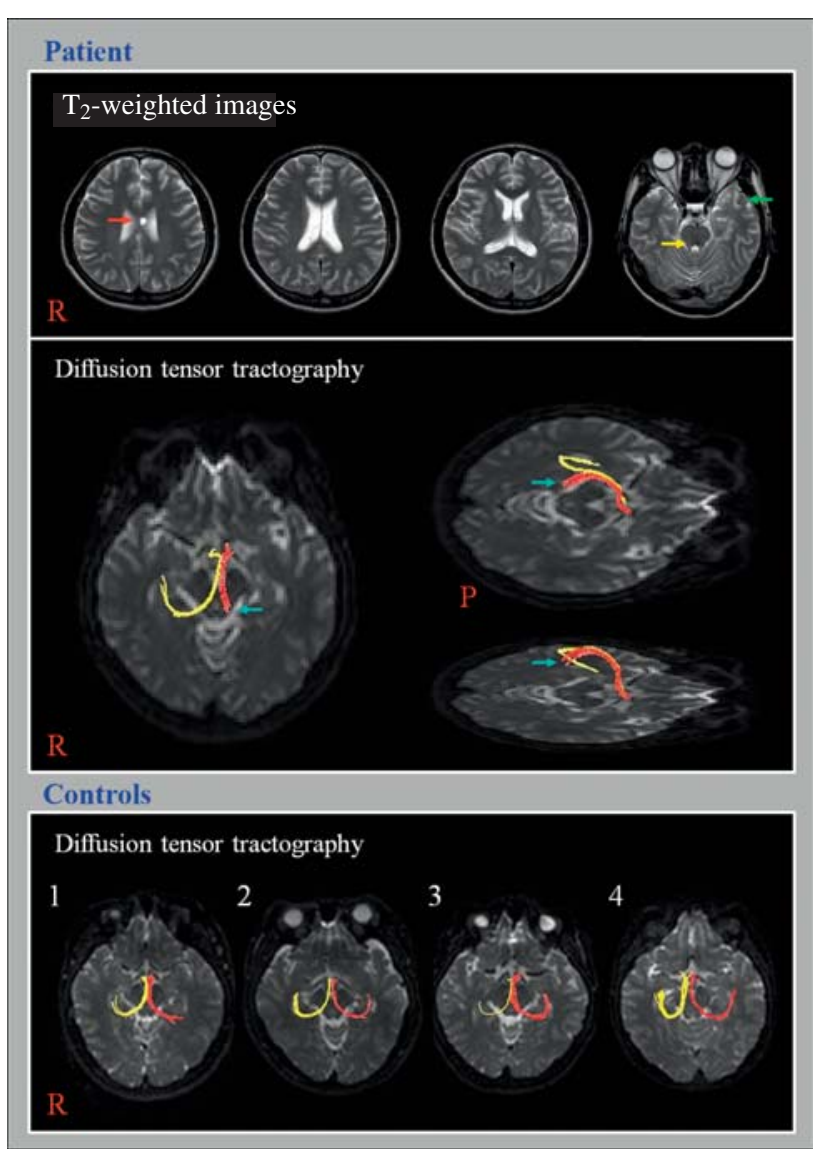

Fig. 1. $\mathrm{T}_{2}$-weighted brain MR images (3 months after onset) show a focal leukomalactic lesion at the corpus callosum (red arrow), and an old hemorrhage at the pons (yellow arrow) and left temporal lobe (green arrow). Diffusion tensor tractography for fornix of the patient show disruption at the left crus (arrow) compared with the intact crus of 4 age- and sex-matched normal controls (4 men, mean age 28.25 years, range $28-29$ ).

\section{KARGER}

Fax +41613061234 E-Mail karger@karger.ch www.karger.com
(C) 2010 S. Karger AG, Basel

0014-3022/10/0634-0252\$26.00/0

Accessible online at:

www.karger.com/ene
Sung Ho Jang, MD

Department of Physical Medicine and Rehabilitation

College of Medicine, Yeungnam University 317-1

Daemyungdong, Namku, Daegu, 705-717 (Republic of Korea)

Tel./Fax +82 53620 3269, E-Mail strokerehab@hanmail.net 